\title{
MATERIAS PRIMAS LÍTICAS Y USO DEL ESPACIO EN LAS NACIENTES DEL RÍO GALLEGOS: EL CASO DE LAGUNA CÓNDOR (ESTANCIA GLENCROSS, SANTA CRUZ, ARGENTINA)
}

JUDITH E. CHARLIN"

\begin{abstract}
RESUMEN
Se presenta el análisis de los materiales líticos de superficie recuperados en la margen noreste de la laguna Cóndor (Estancia Glencross, Santa Cruz, Argentina), localizada en las nacientes del río Gallegos, en un área conocida localmente como los Morros. La metodología implementada, denominada Minimun Analitical Nodules Analysis (Larson y Kornfel 1997), permite agrupar los artefactos y ecofactos por nódulo de roca, lo cual posibilita un análisis de mayor resolución y una cuantificación más precisa de las materias primas líticas explotadas que la agrupación genérica por clase o tipo de roca. Los resultados alcanzados muestran el predominio de nódulos representados por un desecho aislado, en muchos casos en materias primas no-locales, y por conjuntos de desechos en materias primas disponibles en la inmediata vecindad. De acuerdo con los modelos de organización tecnológica propuestos como marco de esta metodología de análisis, los resultados indican, en primer lugar, la reactivación de instrumentos manufacturados y descartados en otro lado que transitaron por el sitio y, en menor proporción, la manufactura y mantenimiento de artefactos in situ que fueron transportados fuera del sitio. Este patrón, junto con otras evidencias, sugieren un uso logístico de este sector del espacio, al menos en momentos históricos, según las dataciones radiocarbónicas disponibles hasta la fecha.
\end{abstract}

PALABRAS CLAVE: morros, materias primas líticas, nódulos, uso del espacio.

\section{LITHIC RAW MATERIALS AND LANDSCAPE USE IN THE UPPER GALLEGOS RIVER: THE CASE OF LAGUNA CÓNDOR (ESTANCIA GLENCROSS, SANTA CRUZ, ARGENTINA)}

\section{ABSTRACT}

The analysis of stone tool from the surface of laguna Cóndor (Estancia Glencross, Santa Cruz, Argentina), located in the upper basin of the Gallegos river, in an area known as los Morros, is presented. The methodology applied, denominated Minimun Analitical Nodules Analysis (Larson y Kornfel 1997), has the advantage of grouping the artifacts and ecofacts by rock nodule, which is more useful than clustering them by class or type of lithic raw material. This method allows us to doing a major resolution 
analysis and a more detailed quantification. The results shown the predominance of nodules represented by only one piece of debitage, in some cases in non-local raw materials, and by sets of debitage in immediately available lithic raw materials. According to the organization models proposed as framework to this methodology, the results point out, at first, the resharpening of tools manufactured and discarded in another place and with a minor rate, in situ manufacture and maintenance of tools, removed of the site and transported far away. This pattern, together with other lines of evidences, suggests a logistic landscape use, at least in historic times, according to the available radiocarbon dating.

KEY WORDS: morros, lithic raw materials, nodules, landscape use.

\section{INTRODUCCIÓN: PROBLEMÁTICA Y OBJETIVOS}

Las nacientes del río Gallegos (Santa Cruz, Argentina) son un área que ha sido escasamente explorada con un interés arqueológico, a pesar de la existencia de numerosas referencias históricas que señalan la presencia de Tehuelches en la zona (ver referencias en Gómez Otero 1991; Martinic 1995). El área es conocida en mayor medida por la existencia de entierros humanos en puntos destacados del paisaje como los morros Philippi, Domeyko, Gay y Chico, este último en territorio chileno (Ortiz Troncoso 1973; Prieto 1984, 1993-1994). Dichos morros son afloramientos volcánicos Miocenos que conforman cerros de basalto y andesita basáltica (D'Orazio et al. 2001). Fuera de estos morros, los pocos trabajos con los que se cuenta hasta la fecha han sido principalmente de superficie (Carballo Marina et al. 2008; Gómez Otero 1991) y con objetivos turísticos (Molinari 2000). Esta situación es contrastante con la abundancia de estudios que se han realizado en el curso medio e inferior de este río (Borrero 1980; Campan et al. 2007; Carballo Marina y Ercolano 2004, 2007; Carballo Marina et al. 2000; Charlin 2009a; Ercolano y Carballo Marina 2005; Ercolano et al. 2000; Gómez Otero y Fontanela 1980; Mansur et al. 2004; Molina 1969-1970, 1976; Sanguinetti de Bórmida 1976, 1976-1980, 1982, 1999; Sanguinetti de Bórmida y Borrero 1977, 1983; entre otros). Frente a este panorama nos preguntamos si la disparidad en la información existente es el resultado, en parte, de un sesgo de muestreo o realmente este sector del espacio ha sido poco explotado por las poblaciones humanas pasadas (Carballo Marina et al. 2008; Gómez Otero 1991). En este marco, se analizaron los materiales líticos recuperados en laguna Cóndor (Estancia Glencross, Santa Cruz, Argentina) a partir de la metodología conocida como Minimun Analytical Nodules Analysis (Larson y Kornfeld 1997), con el objetivo de aproximarnos a la comprensión del uso del espacio a través del estudio de cómo fueron explotadas las materias primas líticas.

\section{ANTECEDENTES DE INVESTIGACIÓN}

Hasta tiempos recientes, la única información arqueológica conocida sobre la zona de estudio era la presencia de entierros humanos en los morros, dados a conocer por viajeros y aficionados. De esta forma, los primeros estudios en el área se ocuparon del análisis de estas colecciones, básicamente de los artefactos recuperados como ajuar de los entierros. Así, Ortiz Troncoso (1973) se ocupó de la descripción de grandes artefactos bifaciales de silex y bolas pulidas, que constituían el ajuar del entierro de al menos tres individuos en morro Philippi. Cabe señalar la presencia de un fragmento de molusco y la ausencia de elementos europeos en el contexto de este sitio (Ortiz Troncoso 1973).

Por otro lado, Prieto (1984) describió en detalle un colgante de lignito decorado con incisiones que fue recuperado, junto con huesos humanos calcinados y 12 lascas de obsidiana verde, en la cima de morro Chico (Estancia Morro Chico, Magallanes, Chile). En el mismo morro, Bate (1970) relevó cuatro concentraciones de representaciones rupestres compuestas por motivos abstractos geométricos en color rojo. Este sitio, junto con otros localizados en el campo volcánico Pali Aike, especialmente en la cuenca del río Chico, pasó a formar parte del "sub-estilo Río Chico", que fue identificado en el extremo sur de Patagonia meridional (Bate 1971). 
Es importante señalar la presencia en ambos morros de elementos que indican su conexión con el ámbito costero, como el fragmento de molusco en morro Philippi y los artefactos en obsidiana verde en morro Chico.

Fuera del ámbito puntual de los morros, en una barranca en el río Penitentes, Molinari (2000) relevó cinco concentraciones de materiales líticos y óseos en hoyadas de deflación, sondeando una de ellas. El conjunto total de materiales se denominó Rincón de Los Morros I (Estancia Rincón de Los Morros, Santa Cruz, Argentina). Molinari destaca la elevada proporción de instrumentos, sobre todo raederas, en basalto y sílice.

Ya en una escala regional de trabajo, Gómez Otero (1991) integra la escasa evidencia recuperada en la zona de los morros a la discusión sobre los límites territoriales de los Proto-Tehuelches y Tehuelches en Patagonia meridional. Los únicos hallazgos registrados en el área por esta investigadora fueron en la ladera oriental del morro Philippi, en las vegas entre el Domeyko y el Philippi, en la costa este de la laguna Cóndor y sobre el fondo de lagunas estacionales más hacia el oriente (Gómez Otero 1991:13). Señala que los hallazgos son tan dispersos que sólo el morro Philippi puede ser considerado como un sitio. Los artefactos allí recuperados están manufacturados en basaltos, sílices y cuarcitas. No se detectó registro arqueológico en el área boscosa.

También Carballo Marina et al. (2008) integran el área a la discusión regional sobre el uso del espacio en la cuenca del río Gallegos, dando a conocer los hallazgos en la laguna Little Hill (Estancia Morro Chico, Santa Cruz, Argentina). Se trata de desechos de talla y artefactos formatizados, manufacturados principalmente en rocas de grano fino oscuras (RGFO, Charlin 2005) y dacita, que fueron recuperados en la margen norte de la laguna. En este caso también se destaca el predomino de los filos largos (raederas y cuchillos) entre los instrumentos. Otras tres lagunas cercanas también fueron prospectadas, pero no se detectaron hallazgos. Cabe señalar la presencia de un asta de huemul en la transecta de la laguna Little Hill, que fue entendida posiblemente como el producto del transporte humano (no presenta modificaciones antrópicas), ya que este sector del espacio no se corresponde con la dispersión actual de este cérvido (Carballo Marina et al. 2008). Sin embargo, durante el Holoceno tardío el área de bosque y ecotono sufrió fluctuaciones, especialmente en la Pequeña Edad de Hielo, por lo cual no puede descartarse la presencia de huemules en la zona (ver Charlin et al. 2011).

En general, la evaluación de la distribución del registro arqueológico a lo largo de la cuenca del Gallegos muestra un decrecimiento en la frecuencia de artefactos en sentido este-oeste, lo cual es entendido en términos de una baja intensidad de uso del curso superior (Carballo Marina et al. 2008; Gómez Otero 1991).

Nuestros trabajos en el área mostraron una distribución discontinua de hallazgos, concentrados en sectores puntuales, como la laguna Cóndor (Borrero y Charlin 2010; Charlin et al. 2011), cuyo análisis de los materiales de superficie aquí se presenta.

\section{ÁREA DE ESTUDIO: LOCALIZACIÓN DE LAGUNA CÓNDOR}

La laguna Cóndor (51ㄴ 45'41.507" S $71^{\circ}$ 38 ' 23.977" W) se localiza en la margen norte del río Turbio, en cercanías de su unión con el río Gallegos. Este último nace de la confluencia de los ríos Rubens y Penitentes y su cauce se desarrolla sobre terrenos depositados a partir del Jurásico (Corbella y Ercolano 2002).

En términos generales la localización de esta laguna puede ser adscripta a la cuenca superior del río Gallegos, el cauce de mayor extensión en la región de estudio (Fig. 1).

Dicha laguna es de origen glaciar, siendo el producto de los avances y retrocesos del lóbulo del río Gallegos durante el Plio-Pleistoceno (Meglioli 1992).

Muchos rasgos geomorfológicos del área son el resultado de la actividad glaciar, como las lagunas en depresiones, las morenas y planicies fluvio-glaciares, los bloques erráticos, entre otros (Meglioli 1992). Sin embargo, es el vulcanismo el que le ha otorgado su marca distintiva a esta región, conocida por la presencia de morros o cerros. Bajo esta denominación se hace referencia a prominentes cuellos volcánicos de edad miocena. Se trata de cinco cerros de basalto subalcalino y andesita basáltica que hicieron erupción entre 8.0-8.5 Ma, denominados Philippi, Chico, Domeyko, Gay y Cuadrado (D'Orazio et al. 2001. Ver Fig. 1). Dicha actividad volcánica es más antigua en ca. 4-5 Ma 


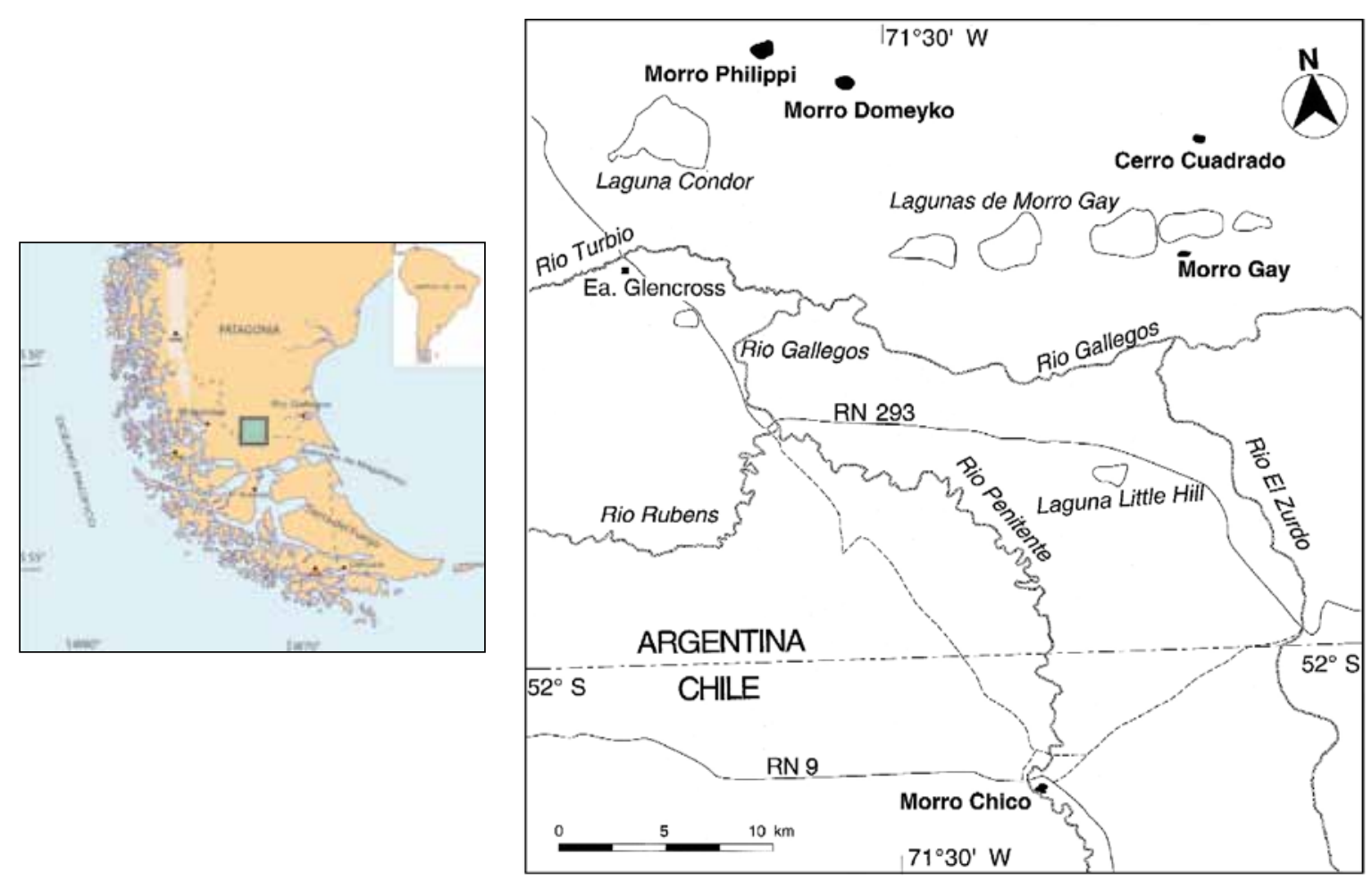

Fig. 1. Localización de la laguna Cóndor en las nacientes del río Gallegos (Santa Cruz, Argentina. Tomado de D'Orazio et al. 2001, con modificaciones).

que la conocida para el campo volcánico Pali Aike (CVPA), localizado aproximadamente a $40 \mathrm{~km}$ al este del morro más oriental (D'Orazio et al. 2001).

En la actualidad la laguna Cóndor se localiza en un área de ecotono bosque-estepa, donde a escasos metros de la laguna se observan remanentes de bosque (Fig. 2). Sin embargo, como fue señalado anteriormente, es necesario tener en cuenta que en momentos de mayor humedad durante el Holoceno tardío, el área de bosque se extendió hacia el oriente (ver referencias en Charlin et al. 2011).

\section{MUESTRA ANALIZADA}

En la margen noreste de la laguna Cóndor, a lo largo de una cárcava en un médano deflacionado, se observó una extensa dispersión de restos culturales, cubriendo un área de $16.500 \mathrm{~m}^{2}$. La cárcava se extiende por $216 \mathrm{~m}$ de largo, aproximadamente a 200 metros de la orilla de la laguna. El relevamiento de los materiales arqueológicos se efectuó mediante unidades de recolección $(n=13)$ identificadas a partir de coordenadas geográficas (Fig. 3). Dado que la dispersión de materiales es amplia, se recolectaron solamente las concentraciones (más de dos piezas líticas en proximidad espacial). En varios casos los artefactos se encuentran asociados con fragmentos de vidrio, metal y restos óseos de fauna (principalmente guanaco, pero también se registra al menos un metapodio de caballo con fractura antrópica,

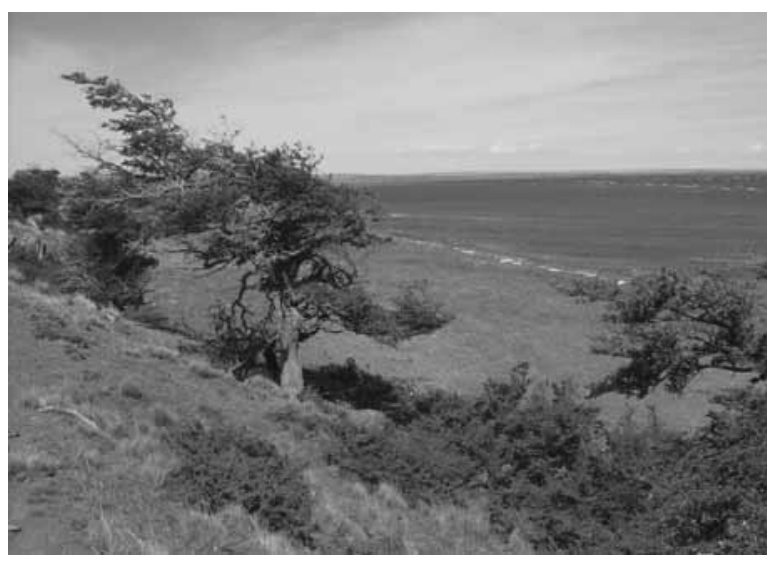

Fig. 2. Remanentes de bosque que se observan actualmente en la margen noreste de la laguna Cóndor. 


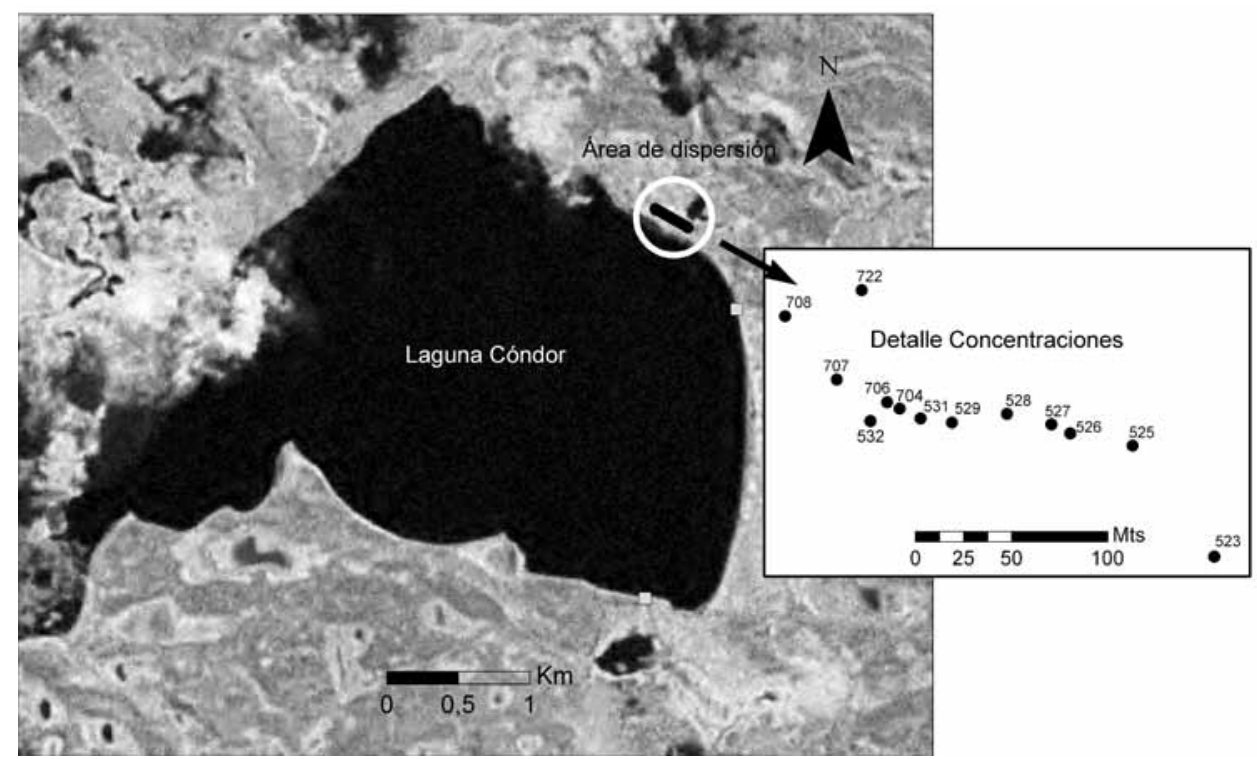

Fig. 3. Localización de los relevamientos efectuados en la laguna Cóndor. Se detalla el área de dispersión de las concentraciones de materiales arqueológicos. Los cuadrados señalan la ubicación de los muestreos de materias primas líticas realizados en las márgenes de la laguna.

L'Heureux com. pers.). Los fechados radiocarbónicos realizados sobre restos óseos de guanaco extraídos del perfil del médano en diferentes loci y profundidades arrojaron edades históricas $(220 \pm 41$ y $187 \pm 41$ años ${ }^{14} \mathrm{C}$ AP, ver más referencias en Charlin et al. 2011).

El total de piezas líticas recolectadas fue de 280, 34 de las cuales corresponden a fragmentos de nódulos de roca producto de shock térmico (siguiendo a Backhouse y Johnson 2007. Ver infra). Se considera que se trata de ecofactos, es decir, nódulos transportados desde la laguna, ya que los mismos no se encuentran disponibles naturalmente en el médano. Descontando estos casos de fragmentos térmicos, que permitieron reconstruír 13 ecofactos, y aquellos en los que varios fragmentos de artefactos pudieron ser reparados (5 casos de reparaciones, sensu Ramos 1993), la muestra queda constituida por 236 artefactos.

\section{MARCO ANALÍTICO Y METODOLOGÍA}

Es de uso corriente en los análisis líticos en arqueología subdividir el conjunto total de artefactos por materia prima. Éste generalmente constituye el primer paso para comenzar a indagar una variedad de temas en diferentes escalas, desde el estudio de las propiedades físico-mecánicas de los tipos de roca seleccionados para la manufactura de los artefactos (cf. Ratto 1991; Ratto y Kligman 1992, entre otros) y sus calidades para la talla (Aragón y Franco 1997), hasta las estrategias de aprovisionamiento y explotación de los recursos líticos por las poblaciones pasadas (Alberti 2010; Borrazzo 2006; Cardillo 2009; Cattáneo 2002; Charlin 2009b; Fernández 2010; Franco 2002, entre otros). Un paso más en la discriminación de las materias primas líticas lo constituye la separación por colores de un mismo tipo de roca, que en algunos casos ha resultado fructífero para el estudio de las fuentes de procedencia (cf. Franco 2002; Franco y Aragón 2002, 2004) y en otros para evaluar el proceso de selección de las materias primas utilizadas para la talla de determinados tipos de instrumentos (Flegenheimer y Bayón 1999). Por último, es posible lograr un nivel de agrupamiento de las materias primas líticas aún más específico por nódulo de roca. Esta metodología de análisis es conocida como análisis nodular o Minimum Analytical Nodules Analysis (en adelante MANA, Larson y Kornfeld 1997) y constituye la forma de segmentación del conjunto de materias primas líticas más específica antes de alcanzar el ensamblaje (sensu Ramos 1993), último paso en la reconstrucción del proceso de producción de artefactos (cf. Larson 1994; Larson y Kornfeld 1997). 
El MANA es uno de los métodos que integra la familia de las metodologías conocidas como Aggregate Analysis (sensu Larson 2004), las cuales se basan en la segmentación de los conjuntos artefactuales, en primera instancia, según criterios no-tecnológicos, tales como categorías de tamaño estandarizadas (tales como size nested screens, grillas de $\mathrm{mm}^{2}$, entre otras), la fragmentación o completitud de los artefactos (Sullivan y Rozen 1983) o el ensamblaje.

La segmentación de los conjuntos de artefactos en nódulos implica generar grupos de similaridad al interior de las clases de materias primas, considerando distintas variables macroscópicas, tales como color, textura, tamaño de grano, inclusiones, corteza, entre otras (Larson 1994; Larson y Kornfeld 1997). La operatividad del MANA depende muchas veces de los tipos de rocas representados en los conjuntos arqueológicos, ya que determinadas clases de materias primas, como algunas rocas silíceas por ejemplo, son más fáciles de agrupar de acuerdo con sus colores e inclusiones distintivos, que otras rocas de características mucho más homogéneas (cf. Larson 1994; Larson y Kornfeld 1997; Larson 2004, aunque opinión contraria en Sario 2009), como las RGFO en nuestro caso de estudio. De todos modos, en estos casos muchas veces es posible identificar el nódulo a través de la textura de la corteza, el tipo de fenocristales (sobre todo por su forma y color) o rasgos diagenéticos, como infiltraciones de otros minerales que conforman venas (ver infra), entre otras variables. Cabe resaltar que, como lo indica su propio nombre, el número mínimo de nódulos es analítico.

Este método de análisis tiene varias potencialidades, permitiendo contestar preguntas tanto relacionadas con la integridad y los procesos de formación de sitio (análisis de la distribución vertical y horizontal de los artefactos) como sobre estrategias tecnológicas (Larson y Kornfeld 1997). El mismo ha sido aplicado tanto a contextos de superficie (Kelly 1985 citado en Larson 1994) como de estratigrafía (Cattáneo 2002, 2004, 2005; Flegenheimer y Cattáneo 2010; Larson 1994; Pautassi y Sario 2010; Sario 2009). En este último caso, el foco del análisis ha estado puesto en diferentes cuestiones. Larson (1994) centra su atención en la relación entre instrumentos fragmentados y nódulos mínimos en Laddie Creek (Wyoming, EEUU), para discutir las actividades de producción, la inversión de trabajo, la conservación de artefactos y las causas de descarte durante el Arcaico temprano. Por otro lado, el estudio de Cattáneo (2002, 2005) sigue un eje temporal, comparando el tipo y número de nódulos y eventos de talla por materia prima y por capa en el Alero El Puesto1 de la localidad Piedra Museo (Santa Cruz, Argentina). Asimismo, el MANA se ha aplicado al estudio de las estrategias tecnológicas de los primeros grupos de cazadores-recolectores del sector occidental de las Sierras de Comechingones (Localidad Arqueológica La Suiza, Prov. San Luis, Argentina), en particular en relación con los modos de producción de artefactos y cómo estos se vinculan con el uso del espacio (Sario 2009).

Flegenheimer y Cattáneo (2010) implementaron esta metodología para comparar los conjuntos de desechos de talla de los grupos tempranos que ocuparon la Pampa húmeda y el sur de Patagonia meridional, con el objetivo de comparar la secuencia de reducción representada en las distintas materias primas líticas explotadas en ambas regiones. Con un fin similar -y contando además con estudios experimentales-, el MANA se ha utilizado para evaluar las estrategias de reducción de núcleos en el componente de $\mathrm{C}$ del sitio Central Nuclear 2 (Prov. Córdoba, Argentina) para el Holoceno tardío (Pautassi y Sario 2010).

Más allá de los distintos casos de análisis, como bien señala Cattáneo (2002, 2005), esta metodología resulta adecuada para el estudio de los conjuntos artefactuales de Patagonia debido al uso prehistórico de clastos como núcleos. De esta forma, el MANA se convierte en un método de análisis especialmente útil en contextos de fuentes secundarias de aprovisionamiento lítico, aunque también ha sido aplicado al estudio de fuentes primarias (Larson 1994).

A continuación se desarrolla una descripción sintética del método, siguiendo a Larson (1994) y Larson y Kornfeld (1997), aunque el mismo ya ha sido presentado en otras oportunidades (Cattáneo 2005, Sario 2009).

\section{Minimum Analytical Nodules Analysis}

Según el tamaño y la composición de los nódulos es posible inferir las estrategias tecnológicas implementadas en la explotación de las diferentes materias primas. Por tamaño se entiende a la cantidad de artefactos por nódulo y por composición 
a las clases de artefactos representadas por nódulo (desechos de talla, núcleos, artefactos formatizados).

Así, en primer lugar, los nódulos pueden ser clasificados en dos tipos según su tamaño: nódulos simples (NS) y nódulos múltiples (NM), según la presencia de un artefacto o más de uno por nódulo, respectivamente. Según su composición, los NS pueden consistir en un desecho de talla, un artefacto formatizado o un núcleo (esta última alternativa no es considerada por Larson y Kornfeld 1997, pero ver infra). Los NM pueden estar compuestos por varios desechos de talla o diferentes combinaciones de desechos, artefactos formatizados y núcleos. A partir de esto es posible caracterizar a cada nódulo de acuerdo con la presencia o ausencia de clases de artefactos. Así, en el caso de NS, si la única pieza presente es un artefacto formatizado se entiende que el mismo fue introducido ya manufacturado al sitio, no sufrió posteriores modificaciones en el mismo (reactivación o reciclaje) y fue descartado allí, haya sido o no usado en el lugar. Esta evidencia puede ser interpretada como el resultado de la pérdida o del descarte intencional de un artefacto conservado (sensu Binford 1979).

Las mismas inferencias se pueden derivar de la presencia de un núcleo solamente, aunque los autores no lo desarrollan. Contemplamos las posibilidades de pérdida o descarte de un núcleo agotado debido al reabastecimiento en cercanías de alguna fuente potencial de aprovisionamiento.

En el caso de un NS representado únicamente por un desecho de talla, el mismo puede ser entendido como una evidencia del paso por el sitio de un artefacto formatizado en otro lado y reactivado en el sitio, pero aún con vida útil, por lo cual continúa siendo transportado y no se descarta en el lugar (Larson y Kornfeld 1997).

Entre los nódulos múltiples se reconocen tres alternativas: 1 . desechos de talla solamente, 2. desechos de talla y núcleo y 3 . desechos de talla, artefacto/s formatizado/s y núcleo (Larson y Kornfeld 1997). Las tres opciones representan la manufactura y/o mantenimiento de artefactos in situ, con las siguientes variantes: mientras los dos primeros casos pueden ser entendidos en el marco de estrategias de conservación de los instrumentos, la alternativa tres representa la secuencia de producción completa, implicando la manufactura, uso y descarte del instrumento en el sitio. Esto representa una estrategia tecnológica expeditiva (Larson y Kornfeld 1997). Nosotros sumamos una opción más, compuesta por un artefacto formatizado junto con sus desechos, que entendemos como el producto del mantenimiento y descarte en el sitio de un instrumento confeccionado en otro lado.

\section{VARIABLES CONSIDERADAS Y PROCEDIMIENTOS DE ANÁLISIS}

Los artefactos fueron clasificados en clases y grupos tipológicos según variables tecno-morfológicas (Aschero 1975, 1983; Aschero y Hocsman 2004) y agrupados por nódulo y por materia prima lítica. Las mismas fueron determinadas a partir de cortes delgados realizados sobre muestras de artefactos seleccionadas $(n=12)$ y sobre muestras naturales recolectadas en las márgenes de la laguna $(n=6$, ver infra). La identificación petrográfica estuvo a cargo de la Dra. M. C. Etchichury (Sección Petrografía, Museo Argentino de Ciencias Naturales Bernardino Rivadavia). En la selección de las muestras el énfasis estuvo puesto en las RGFO, que son las materias primas de mayor homogeneidad macroscópica y por lo tanto más difíciles de diferenciar. Para la separación por nódulo se utilizaron las siguientes variables (cf. Scasso y Limarino 1997):

- el color, la tonalidad, el tamaño de grano y la textura de la roca

- la forma y el color de los fenocristales en el caso de texturas porfíricas

- el color, la tonalidad y el tipo de corteza

- la calidad de la roca para la talla (Aragón y Franco 1997);

- la pátina

- la presencia de oxidación y de infiltraciones bajo la forma de vetas

Asimismo se evaluaron las posibilidades de ensamblaje entre las piezas de un mismo nódulo siguiendo la propuesta de Ramos (1993) de diferenciar entre la reparación y el remontaje. En los casos de reparación se registró si la superficie de fractura era fresca o estaba patinada.

En cada artefacto se relevó el estado de conservación, el largo, ancho y espesor máximos (en $\mathrm{mm}$ ) con calibre digital, el porcentaje de corteza, la cantidad de filos y/o puntas formatizados $y / o$ con rastros complementarios por pieza y la cantidad de 
extracciones previas en la cara dorsal en los desechos de talla e instrumentos y en la totalidad de las superficies implicadas en el caso de los núcleos. Esta última variable es utilizada para calcular la densidad de extracciones en relación con el tamaño de los artefactos (estimado a partir del área en el caso de desechos e instrumentos y del volumen en los núcleos. Ver detalles sobre el cálculo de este índice en Charlin 2009b).

\section{DESCRIPCIÓN DE LA MUESTRA}

\section{Clases tipológicas}

La muestra de artefactos se encuentra compuesta por siete núcleos, 193 desechos de talla, 27 artefactos formatizados (24 unifaciales y tres bifaciales -incluyendo una preforma de punta de proyectil-), dos artefactos sin formatización con rastros complementarios y 7 litos modificados por uso (percutores). La composición de las clases tipológicas por tipo de artefacto y materia prima puede verse en la tabla 1 .

\section{Materias primas líticas}

Las materias primas principalmente utilizadas son las RGFO, en primer lugar, seguidas por la dacita (tabla 2). Esta tendencia es la misma que en el cercano campo volcánico Pali Aike (Charlin 2009b). Sin embargo, cabe señalar dos factores distintivos de las RGFO en laguna Cóndor. Por un lado, a diferencia de Pali Aike, entre las variedades petrográficas incluidas en el conjunto de las RGFO, aquí predominan las rocas sedimentarias (lutitas y fangolitas), mientras que en Pali Aike se destacan las variedades volcánicas (dacitas y basaltos, Charlin et al. 2010; Charlin y D'Orazio 2011). Entre las RGFO sedimentarias domina ampliamente la lutita (tabla 3). Este tipo de roca también se encuentra representado con frecuencia en otros colores. En las tablas 1,2 y 4, aquellas rocas denominadas lutita y basalto corresponden a variedades de color diferente al negro. Las lutitas y los basaltos negros están incluidos dentro del conjunto de las RGFO. Esta tendencia en el predominio de las RGFO sedimentarias hacia el occidente, en el sur de Patagonia meridional, también ha sido registrada más al norte, hacia el SE de la sierra Baguales (Estancia La Verdadera Argentina, Borrazzo 2006, 2008), donde estas rocas se encuentran disponibles en mayores tamaños $y$ al parecer en mejores calidades para la talla -al menos considerando comparativamente los nódulos recuperados tan solo en dos muestreos realizados en laguna Cóndor (ver infra)-. Por consiguiente, la abundancia relativa de una variedad u otra de RGFO en los distintos sectores del sur de Patagonia se encuentra relacionada con la disponibilidad local de estas rocasi. Una variedad de RGFO volcánica -la más explotada en el CVPA-, denominada "tipo PKA" (Potrok Aike, por la abundancia de esta variedad en la laguna citada, lo cual sugiere su cercanía a la fuente primaria de procedencia. Charlin y Pallo 2012) no ha sido detectada en los muestreos naturales realizados en la laguna y entre los artefactos se encuentra representada en escasos ejemplares $(n=10$. Ver infra). Esto sugiere una procedencia nolocal de esta roca y el transporte de los artefactos desde otros sectores del espacio.

Por otro lado, es de destacar la ocurrencia en laguna Cóndor de un proceso de silicificación intenso que ha afectado tanto a las RGFO de naturaleza volcánica como sedimentaria, y también a otros tipos de rocas (1, tablas 2 y 4). De acuerdo con las referencias de Ortiz Troncoso (1973) sobre grandes artefactos bifaciales de silex, con corteza en una o ambas caras, en morro Philippi y la presencia de dos núcleos de ftanita en las recolecciones de laguna Cóndor, probablemente esta roca se encuentre disponible en el área, a pesar que en los muestreos de rocas realizados no haya sido recuperada.

Es necesario en esta instancia hacer una aclaración sobre la nomenclatura de las rocas silíceas. Adoptamos la denominación de ftanita acuñada por Teruggi (1984:161) frente a la variedad de términos utilizados para hacer referencia a las rocas silíceas de grano fino (tales como chert, pedernal, silex, flint). Ftanita, en sentido amplio, comprende a las rocas silíceas de distinta génesis, es decir, tanto aquellas formadas por precipitación inorgánica (directa y metasomática) y bioquímica como también por acumulaciones biogénicas (Teruggi 1984). Rocas volcánicas y sedimentarias silicificadas, en los casos en los que no pudo ser determinada su petrografía, fueron incluídas también bajo esta denominación.

\footnotetext{
1 Sin embargo resta evaluar el caso de grandes raederas en RGFO sedimentaria recuperadas en cañadón Gap (costa Atlántica), debido a que este tipo de roca no se encuentra disponible con frecuencia en el área, al menos en tamaños comparables a los de los artefactos.
} 


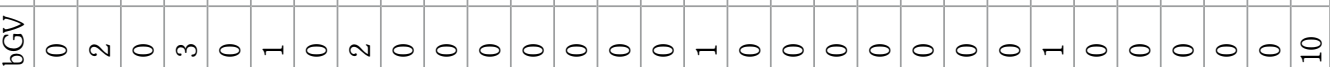


Tabla 2. Frecuencia de materias primas líticas representadas en el total de la muestra de laguna Cóndor (total de piezas sin reparación, incluyendo artefactos y ecofactos).

\begin{tabular}{|l|c|}
\hline Materia prima & $\mathrm{n}$ \\
\hline RGFO* & 114 \\
\hline Dacita* & 48 \\
\hline Lutita & 27 \\
\hline Andesita & 21 \\
\hline Ftanita & 28 \\
\hline Obsidiana (10 gris- verdosa veteada, 2 verde) & 12 \\
\hline Arenisca & 7 \\
\hline Toba & 7 \\
\hline Madera silicificada & 5 \\
\hline Calcedonia & 4 \\
\hline Basalto & 2 \\
\hline Roca granítica & 2 \\
\hline Roca metamórfica & 1 \\
\hline Pelita & 1 \\
\hline Indeterminada & 1 \\
\hline Total & 280 \\
\hline & \\
\hline
\end{tabular}

Por último, con respecto a la tabla 2 , cabe señalar la posición de las obsidianas en el ranking de materias primas, destacándose la variedad grisverdosa veteada, probablemente procedente de la sierra Baguales (Stern y Franco 2000). Este tipo de roca también nos permite establecer semejanzas con el CVPA, donde es la variedad de obsidiana más abundante (Charlin 2009c). En comparación con los sitios relevados en Pali Aike, laguna Cóndor es el contexto más cercano a la supuesta área de procedencia de la obsidiana gris-verdosa veteada. Es notorio que en contextos más próximos a la probable fuente, como Cerro León 1 y 3 (Estancia La Verdadera Argentina, Borrazzo 2006; Borrero et al. 2006), no se registre esta variedad de obsidiana. En una transecta realizada en esta zona, se

Tabla 3. Variedades de RGFO identificadas en la muestra de laguna Cóndor (total de piezas sin reparación).

\begin{tabular}{|l|c|}
\hline Variedad de RGFO & $\mathrm{n}$ \\
\hline sedimentaria (al menos 32 lutitas y 8 fangolitas) & 65 \\
\hline sedimentaria silicificada (9 lutitas silicificadas) & 9 \\
\hline volcánica (al menos 11 basaltos y 2 dacitas) & 23 \\
\hline volcánica silicificada & 12 \\
\hline silicificada (génesis indeterminada) & 4 \\
\hline Indeterminada (por pátina intensa) & 1 \\
\hline Total & 114 \\
\hline
\end{tabular}

ha recuperado en superficie un desecho de talla en obsidiana gris, el cual por el momento no puede ser asignado a la variedad gris-verdosa veteada ante la ausencia de una determinación geoquímica (Borrazzo com. pers.). Obsidiana gris en diferentes tonalidades, de fuente aún desconocida, también es frecuente en CVPA. Una lasca secundaria en obsidiana gris oscura ha sido determinada por Stern (com. pers. 2009) como un tipo diferente al grisverdoso veteado -de Baguales-, y al gris traslúcido identificado en una lasca de la colección Bird de la cueva Pali Aike (Stern 2004).

Con respecto a la disponibilidad local de rocas, se han efectuado dos muestreos en la margen sur y este de la laguna, por una persona durante 10 minutos (Franco y Borrero 1999. Ver Fig. 2). En la tabla 4 se presenta la abundancia relativa de los distintos tipos de roca y en la tabla 5 la determinación petrográfica de los cortes delgados realizados sobre muestras artefactuales y naturales. Como puede observarse, la mayoría de las materias primas líticas utilizadas para la manufactura de artefactos se encuentran disponibles localmente. Es posible obtener prácticamente todas ellas en la inmediata vecindad. Esto, sumado a la recuperación de un núcleo en dacita en el muestreo de la margen sur de la laguna, nos permite sostener la explotación efectiva de esta fuente de aprovisionamiento.

Tabla 4. Disponibilidad de materias primas líticas en las márgenes de laguna Cóndor.

\begin{tabular}{|l|c|c|}
\hline \multicolumn{1}{|c|}{ Tipo de roca } & Margen sur & Margen este \\
\hline Andesita & 6 & 2 \\
\hline Basalto & 2 & 1 \\
\hline Cuarzo & 1 & 0 \\
\hline Dacita & 17 & 33 \\
\hline Diabasa & 1 & 0 \\
\hline Jaspe & 0 & 1 \\
\hline Lutita & 4 & 4 \\
\hline RGFO & 6 & 8 \\
\hline sedimentaria & 5 & 5 \\
\hline volcánica & 1 & 2 \\
\hline silicificada (génesis & 0 & 1 \\
\hline indeterminada) & 2 & 0 \\
\hline Roca metamórfica & 0 & 2 \\
\hline Riolita & 0 & 1 \\
\hline Roca granítica & 1 & 1 \\
\hline Toba & 2 & 0 \\
\hline Vulcanita & 42 & 53 \\
\hline Total & & \\
\hline
\end{tabular}


Tabla 5. Determinación petrográfica de los cortes delgados realizados sobre artefactos y nódulos de roca recuperados en los muestreos de materias primas.

\begin{tabular}{|l|c|l|l|l|}
\hline \multicolumn{1}{|c|}{ Procedencia } & № inv. & \multicolumn{1}{|c|}{ Tipo de pieza } & \multicolumn{1}{c|}{ Determinación Petrográfica } & Color \\
\hline Laguna Cóndor & 532.28 & desecho & Lutita & negro (RGFO) \\
\hline Laguna Cóndor & 532.30 & desecho & Basalto & negro (RGFO) \\
\hline Laguna Cóndor & 532.38 & desecho & Fangolita & negro (RGFO) \\
\hline Laguna Cóndor & 532.45 & desecho & Fangolita & negro (RGFO) \\
\hline Laguna Cóndor & 532.44 & desecho & Lutita silicificada & negro (RGFO) \\
\hline Laguna Cóndor & 532.43 & Artef. Formatizado & Lutita & negro (RGFO) \\
\hline Laguna Cóndor & 532.42 & desecho & Lutita & negro (RGFO) \\
\hline Laguna Cóndor & 529.19 & núcleo & Ftanita/Chert & gris \\
\hline Laguna Cóndor & 526.3 & desecho & Roca silicificada & negro (RGFO) \\
\hline Laguna Cóndor & 523.13 & desecho & Lutita & verde grisáceo \\
\hline Laguna Cóndor & 527.2 & desecho & Roca silicificada de origen volcánico & negro (RGFO) \\
\hline Laguna Cóndor & 531.32 & desecho & Roca silicificada & negro (RGFO) \\
\hline Sur Lg. Cóndor & 42 & nódulo (muestreo) & Roca silicificada de origen volcánico & negro (RGFO) \\
\hline Sur Lg. Cóndor & 5 & nódulo (muestreo) & Pelita fisurada & negro (RGFO) \\
\hline Sur Lg. Cóndor & 29 & nódulo (muestreo) & Lutita & gris \\
\hline Este Lg. Cóndor & 24 & nódulo (muestreo) & Pelita silicificada & negro (RGFO) \\
\hline Este Lg. Cóndor & 48 & nódulo (muestreo) & Roca silicificada posiblemente de origen volcánico & negro (RGFO) \\
\hline Este Lg. Cóndor & 49 & nódulo (muestreo) & Roca silicificada posiblemente de origen volcánico & negro (RGFO) \\
\hline
\end{tabular}

\section{RESULTADOS}

\section{Análisis nodular o MANA}

A partir del agrupamiento del total de la muestra recuperada (artefactos y ecofactos) por materia prima y luego por rasgos más específicos, fue posible identificar un número mínimo de 141 nódulos, siendo 13 el número de nódulos reconstruido a partir de fragmentos térmicos (entendidos como ecofactos) y 128 a partir de artefactos. Entre los fragmentos térmicos se identificaron seis nódulos simples (NS), constituidos por desechos aislados, y siete nódulos múltiples (NM), conformados por

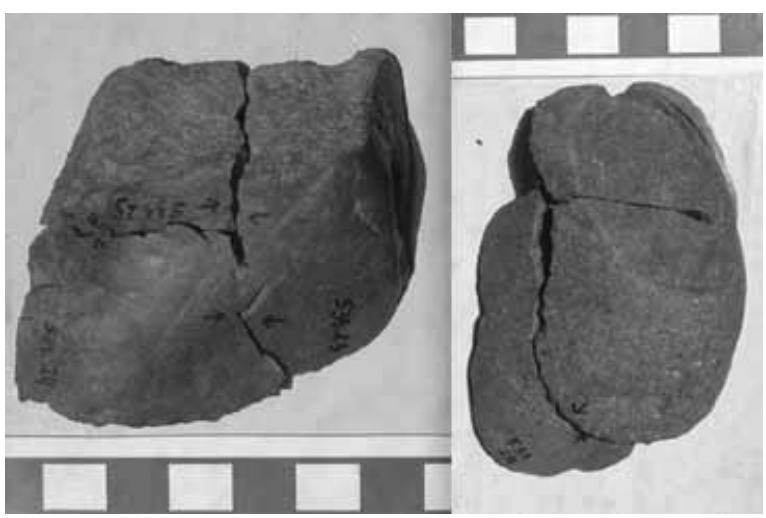

Fig. 4. Casos de fragmentos térmicos de ecofactos reparados y/o remontados. conjuntos de desechos del mismo nódulo. En tres casos (correspondientes a distintos nódulos) los fragmentos térmicos pudieron ser reparados y en otros dos casos (uno de ellos correspondiente a dos fragmentos térmicos que previamente habían sido reparados en una lasca térmica) fueron remontados a través de las superficies de exfoliación (Fig. 4). En la tabla 6 se presenta la distribución de materias primas líticas en estos nódulos, ya que no son considerados en las descripciones que siguen. Los únicos tipos de rocas presentes en los fragmentos térmicos que no se encuentran representados entre los artefactos son la arenisca y la roca granítica.

Tabla 6. Materias primas líticas representadas en los fragmentos térmicos de ecofactos (total de piezas sin reparación).

\begin{tabular}{|l|c|}
\hline Materia prima & $\mathrm{n}$ \\
\hline Andesita & 12 \\
\hline Arenisca & 7 \\
\hline Dacita & 7 \\
\hline Roca granítica & 2 \\
\hline Ftanita & 2 \\
\hline Toba & 2 \\
\hline Lutita & 1 \\
\hline RGFO sedimentaria & 1 \\
\hline Total general & 34 \\
\hline
\end{tabular}


En la muestra de artefactos se identificaron 75 NS y 53 NM. En la tabla 7 se puede observar la composición de los distintos tipos de nódulos agrupados por materia prima lítica, excluyendo los casos de fragmentos térmicos.

Se registran seis casos de materias primas líticas que solamente se encuentran representadas entre los NS. Se trata de obsidiana verde, pelita indeterminada, roca metamórfica, RGFO indeterminada, roca indeterminada y basalto. La falta de una determinación petrográfica más precisa de varias de estas materias primas se debe a que se encuentran patinadas, lo cual dificulta en gran parte su identificación y posiblemente su agrupación con otros artefactos del mismo nódulo. Esto puede ocasionar que la cantidad de materias primas representadas únicamente por NS se encuentre sobreestimada, aunque los artefactos pertenecientes a un mismo nódulo suelen responder de la misma manera a la meteorización, por lo cual podrían ser identificados a partir del mismo tipo de pátina. De todos modos, siendo conservadores, esta cantidad debe considerarse como un número máximo.

En los primeros cinco casos mencionados, estas rocas se encuentran representadas solo por desechos aislados, en tanto que en el último se trata de un núcleo y un instrumento en distintos nódulos.

Por otro lado, hay un caso que solamente se encuentra representado en las materias prima entre los NM: la madera silicificada, representada por varios desechos del mismo nódulo.

Las únicas materias primas que comprenden la mayor diversidad de tipos de nódulos según composición son la ftanita y las RGFO (tabla 7), lo cual sugiere una variabilidad de comportamientos en la explotación de estas rocas, probablemente relacionada con su disponibilidad local.

RGFO, dacita y ftanita son los tipos de rocas en los que se identificó la mayor frecuencia de nódulos, por consiguiente se trata de las materias primas más explotadas. Las RGFO (51 nódulos en total), se encuentran principalmente representadas por conjuntos de desechos (22 nódulos) y por desechos aislados (14 nódulos), lo cual sugiere la manufactura de artefactos en el lugar y su transporte fuera del sitio y el mantenimiento de instrumentos que formarían parte del toolkit transportado. En la dacita (26 nódulos en total) y en la ftanita (18 nódulos en total) se destacan los desechos aislados (que dan cuenta de 14 y 7 nódulos, respectivamente), entendidos como indicadores de mantenimiento. Sin embargo, la ftanita muestra un panorama diferente en tanto también se encuentran representados en menor frecuencia nódulos compuestos por un núcleo aislado y un núcleo+desechos, los que están ausentes entre las dacitas y sugieren la manufactura de artefactos en ftanita in situ, que habrían sido descartados en otro lado.

Tabla 7. Composición de los nódulos simples y múltiples por materia prima lítica (muestra artefactual).

\begin{tabular}{|c|c|c|c|c|c|c|c|c|c|c|}
\hline \multirow{3}{*}{ Materia prima* } & \multirow{2}{*}{\multicolumn{4}{|c|}{ Nódulos simples }} & \multirow{2}{*}{\multicolumn{5}{|c|}{ Nódulos múltiples }} & \multirow{3}{*}{$\begin{array}{c}\mathrm{NMN}^{+} \text {por } \\
\text { Materia prima }\end{array}$} \\
\hline & & & & & & & & & & \\
\hline & $\mathrm{D}$ & I & $\mathrm{N}$ & Total NS & Ds & $\mathrm{I}+\mathrm{Ds}$ & $\mathrm{Ds}+\mathrm{N}$ & $\mathrm{Ds}+\mathrm{N}+\mathrm{I}$ & Total NM & \\
\hline Andesita & 2 & 4 & 0 & 6 & 0 & 1 & 0 & 0 & 1 & 7 \\
\hline Basalto & 0 & 1 & 1 & 2 & 0 & 0 & 0 & 0 & 0 & 2 \\
\hline Calcedonia & 1 & 0 & 0 & 1 & 0 & 1 & 0 & 0 & 1 & 2 \\
\hline Dacita & 14 & 5 & 0 & 19 & 6 & 1 & 0 & 0 & 7 & 26 \\
\hline Ftanita & 7 & 4 & 1 & 12 & 3 & 2 & 1 & 0 & 6 & 18 \\
\hline Indeterminada & 1 & 0 & 0 & 1 & 0 & 0 & 0 & 0 & 0 & 1 \\
\hline Lutita & 2 & 2 & 0 & 4 & 3 & 1 & 0 & 0 & 4 & 8 \\
\hline MadSil & 0 & 0 & 0 & 0 & 1 & 0 & 0 & 0 & 1 & 1 \\
\hline Ob. gris verdosa & 2 & 0 & 1 & 3 & 2 & 1 & 0 & 0 & 3 & 6 \\
\hline Ob. verde & 1 & 0 & 0 & 1 & 0 & 0 & 0 & 0 & 0 & 1 \\
\hline RGFO & 14 & 6 & 2 & 22 & 22 & 6 & 1 & 0 & 29 & 51 \\
\hline RMet & 1 & 0 & 0 & 1 & 0 & 0 & 0 & 0 & 0 & 1 \\
\hline Pelita & 1 & 0 & 0 & 1 & 0 & 0 & 0 & 0 & 0 & 1 \\
\hline Toba & 3 & 0 & 0 & 3 & 1 & 0 & 0 & 0 & 1 & 4 \\
\hline $\begin{array}{l}\text { Total nódulos por } \\
\text { composición }\end{array}$ & 48 & 22 & 5 & 75 & 38 & 13 & 2 & 0 & 53 & 128 \\
\hline
\end{tabular}


Las materias primas restantes muestran distintas combinaciones de tipos de nódulos, pero nos interesa destacar en particular el caso de la obsidiana gris-verdosa veteada. La misma se encuentra representada en tres NS -correspondientes a dos desechos aislados y un núcleo- $y$ en tres NM -compuestos por dos conjuntos de desechos sobre diferentes nódulos y un artefacto formatizado junto con sus desechos de talla perteneciente a otro nódulo-. Este último caso es interesante en tanto se trata de una preforma de punta de proyectil, con presencia de corteza en la base del pedúnculo, asociada a una lasca de adelgazamiento bifacial (con un 10\% de corteza en su cara dorsal) y una lasca de arista (sin corteza), la primera de las cuales remonta en una charnela de la preforma (ver Fig. 6.2). Uno de los conjuntos de desechos mencionado está constituido por dos lascas secundarias con 40 y $50 \%$ de corteza, en tanto que el otro presenta una lasca angular y una de adelgazamiento bifacial, ambas sin corteza. En los dos casos de desechos aislados, la presencia de corteza de diferente tipo fue lo que permitió diferenciarlos (20 y 25\% de corteza respectivamente). En otro lado (Charlin 2009c), donde se discutieron los diferentes modos de explotación de las variedades de obsidiana en el CVPA, se mantuvo el interrogante en cuanto a la forma de obtención de la variedad gris-verdosa veteada, ya que si bien es la más abundante, también es la que presenta los mayores grados de reducción en los desechos de talla y los menores porcentajes de corteza, en comparación con las obsidianas negra y verde. Las clases de artefactos representadas en laguna Cóndor y el análisis nodular desarrollado -que permitió identificar la explotación efectiva de al menos seis nódulos de esta roca- nos permiten sostener el aprovisionamiento directo de la obsidiana gris-verdosa veteada y el transporte de nódulos o núcleos ${ }^{2}$.

\section{Nódulos Simples}

Más de la mitad de la muestra de nódulos se encuentra conformada por NS (59\%), lo cual indica una baja frecuencia en el sitio de nódulos representados por más de un artefacto. El 64\% $(n=48)$ de los NS son desechos aislados, entre los que predominan los procedentes de diferentes nódulos de dacita $(\mathrm{n}=14)$ y RGFO ( $\mathrm{n}=14)$.

2 Cabe recordar la presencia de un núcleo sobre esta variedad de obsidiana, determinada geoquímicamente, en el alero Frailes 2, CVPA (Charlin 2009a).
Esta tendencia parecería sugerir más el tránsito de artefactos por el lugar que el desarrollo completo de la secuencia de producción de artefactos en el sitio, aunque la presencia de percutores, junto con otros indicadores, apuntan hacia el desarrollo de al menos ciertas etapas de manufactura in situ sobre determinadas materias primas líticas de disponibilidad local (ver infra).

El 29\% ( $n=22)$ de los NS se encuentra constituido por instrumentos aislados, es decir, instrumentos descartados en el lugar sin ningún otro tipo de artefacto del mismo nódulo asociado. Entre los mismos se pueden diferenciar dos subconjuntos de acuerdo con la inversión tecnológica en su manufactura.

Por un lado, encontramos 16 artefactos con baja inversión en su manufactura, confeccionados principalmente sobre formas-base naturales $(n=12)$ y lascas iniciales (primarias y secundarias, $n=3$ ), por lo tanto con un número bajo de extracciones previas a la de la forma-base (la mayoría directamente carecen de extracciones), con elevados porcentajes de corteza (100-60\%), ausencia de evidencias de reactivación (sólo se registran dos casos según lo especificado en Charlin 2007), calidad regular de las rocas para la talla y baja frecuencia de filos activos por instrumento. Estas características, sumado a que la mayoría de estos instrumentos fueron descartados enteros, señalan su potencial para seguir siendo utilizados, es decir, aún conservan vida útil remanente, lo cual sugiere una estrategia de equipamiento de sitio (sensu Binford 1979) o aprovisionamiento de lugares (sensu Kuhn 2004).

En este conjunto, las formas-base naturales son nódulos bajo la forma de gravas y lajas. Siete de estos casos son percutores, clasificados como clase tipológica en "litos modificados por uso", ya que no se encuentran formatizados, tratándose de nódulos con $100 \%$ de corteza que presentan rastros de percusión en las caras $(n=1)$, en las aristas $(n=4)$ y combinados $(n=2)$. Algunos nódulos parecen haber sido seleccionados para esta función según su forma prolada (Scasso y Limarino 1997), que facilita la prehensión. Los cinco casos restantes de utilización de formas-base naturales son artefactos formatizados, pero con baja inversión en su manufactura, ya que en general no registran extracciones más que para la formatización del filo, a saber, dos chopping tools, un chopper, un cepillo y un cuchillo. 
A diferencia de este conjunto, el resto de los instrumentos aislados $(n=6)$ presentan por lo general dos filos formatizados $(n=3)$ o son puntas de proyectil bifaciales ( $n=2)$, están manufacturados todos ellos sobre materias primas de calidades excelente $(n=1)$ y muy buena ( $n=5)$, sobre formas-base en estadios avanzados de reducción del núcleo -con numerosas extracciones previas-o retomadas (en un caso), presentan evidencias de reactivación $(n=5)$ y ausencia o escasez de corteza (0-30\%). Los mismos pueden ser entendidos como instrumentos conservados (Binford 1979).

Si comparamos el tamaño de los instrumentos enteros (a través de la media geométrica) entre ambos grupos, las diferencias son notables (tabla 8). Mientras el grupo 1 tiene una media de 74,52 $\mathrm{mm}$, con la mitad de la muestra comprendida entre $60-88 \mathrm{~mm}$, alcanzando un máximo de 104,62 mm, el grupo 2 presenta tamaños más pequeños, con una media de $32,71 \mathrm{~mm}$ y el $50 \%$ de los artefactos con tamaños entre 18-44 mm. Estos valores permiten considerar a los instrumentos del grupo 2 como transportables, en tanto que muchos de los instrumentos del grupo 1 (especialmente choppers, choppings tools y cepillo), debido a su mayor tamaño, se convierten en inadecuados para su traslado y pueden considerarse como parte del equipamiento del lugar.

Por último, los núcleos aislados representan el $7 \%(n=5)$ de los NS. Se trata de un núcleo con lascados aislados en basalto, un núcleo bipolar en ftanita, un núcleo discoidal en RGFO sedimentaria silicificada y dos núcleos poliédricos, uno en obsidiana gris-verdosa veteada y otro en RGFO sedimentaria.

\section{Nódulos Múltiples}

Entre los NM abundan los conjuntos de desechos (72\%), principalmente en RGFO y dacita, lo

Tabla 8. Estadística descriptiva del tamaño (media geométrica) de los instrumentos enteros en los conjuntos diferenciados según la inversión en su manufactura.

\begin{tabular}{|l|c|c|}
\hline Estadística descriptiva & Conjunto 1 & Conjunto 2 \\
\hline $\mathrm{N}$ & 14 & 4 \\
\hline Tamaño Mínimo & 38,89 & 14,64 \\
\hline Tamaño Máximo & 104,62 & 44,20 \\
\hline Media aritmética & 74,52 & 32,71 \\
\hline Varianza & 392,55 & 183,80 \\
\hline Desvío estándar & 19,81 & 13,56 \\
\hline Mediana & 75,83 & 35,99 \\
\hline Percentil 25 & 59,72 & 18,48 \\
\hline Percentil 75 & 87,89 & 43,64 \\
\hline
\end{tabular}

cual sugiere la manufactura de instrumentos sobre estas materias primas y su transporte. De hecho, las evidencias de explotación efectiva de la laguna como fuente de aprovisionamiento sugiere el desarrollo de actividades de reemplazo de instrumentos.

En segundo lugar se posicionan los nódulos conformados por instrumento/s junto con sus desechos (22\%), con la mayor frecuencia en las RGFO. En solo dos casos (un nódulo de RGFO y otro de ftanita) se recuperaron los núcleos y desechos del mismo nódulo. Ambas situaciones sugieren la manufactura in situ y el transporte del núcleo o del instrumento fuera del sitio. Es notable la ausencia de la secuencia de reducción completa entre los $\mathrm{NM}$, es decir, no se registra ningún caso en el que se haya recuperado el núcleo, los desechos de talla y el/los instrumento/s del mismo nódulo.

Entre los NM se destacan el caso la obsidiana gris-verdosa veteada, que ya fue reseñado anteriormente.

Relaciones espaciales: distribución de nódulos y casos de ensamblaje

A pesar de tratarse de un contexto de médano, la integridad de los conjuntos es elevada. En la mayoría de los casos las piezas que forman parte del mismo nódulo se encuentran dentro de los límites de la concentración; lo mismo sucede con los casos de reparaciones $(n=5)$ y remontajes $(n=13)$. Sobre el total de 141 nódulos identificados, tan solo 9 de ellos (6\%) presentan piezas dispersas en diferentes concentraciones (Fig. 5) y solo se registra un caso de remontaje entre dos piezas recuperadas en distintos conjuntos. La figura 5 muestra la dispersión

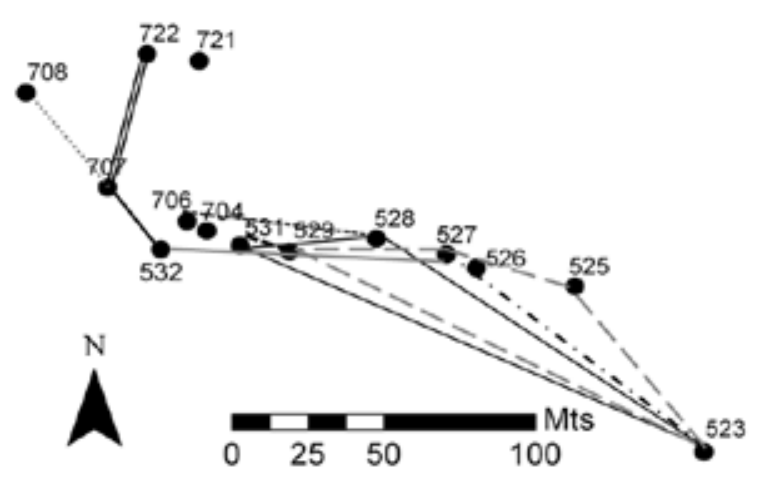

Fig. 5. Dispersión de piezas del mismo nódulo entre concentraciones. 
de piezas del mismo nódulo entre concentraciones. Esta dispersión no parece responder a la pendiente, en tanto prácticamente no se registran diferencias de altura a lo largo del área de recolección. Ambos extremos de la cárcava tienen una altura de 134 msnm (unidades 708 y 523).

Además de esta asociación espacial relacionada con la secuencia de reducción de los nódulos, es de notar la concentración de piezas del mismo tipo en algunas unidades. Es el caso de los fragmentos térmicos $(n=34)$, recuperados la mayoría de ellos en la unidad de recolección 531 ( $n=30$, dando cuenta de 11 nódulos) y en otras dos unidades cercanas ( $n=3$ en unidad 529 y $n=1$ en unidad 528). La concentración espacial de estos fragmentos, junto con indicadores tales como las características de la superficie de fractura, la coloración, la forma y el peso de los fragmentos (de acuerdo con los indicadores derivados de la experimentación realizada por Blackhouse y Johnson 2007, entre otros) nos conduce a entenderlos como el resultado de la fractura por shock térmico de piedras de fogón.

Una situación similar se registra en la distribución de los percutores $(n=7)$ : seis fueron recuperados en la concentración 722 , en tanto que el séptimo corresponde a la 526.

- De los casos de ensamblaje (tabla 9) nos interesa destacar dos casos de remontaje entre un desecho de talla y un instrumento y un caso de remontaje entre un desecho de talla y un núcleo, que evidencian actividades de manufactura y mantenimiento en el sitiel remontaje de una lasca de reactivación de núcleo sobre un núcleo poliédrico de ftanita gris con motas negras de calidad excelente (Fig. 6.1).

- el remontaje de una lasca de adelgazamiento bifacial en una preforma de punta de proyectil en obsidiana gris-verdosa veteada de calidad excelente, que ya fue mencionado (Fig. 6.2).

- el remontaje de una lasca de reactivación directa en el filo de un raspador en ftanita blanco cremoso de calidad excelente (Fig. 6.3).

Sólo a modo descriptivo, también podemos señalar que en muchos casos se registró el remontaje entre lascas reparadas previamente.

\section{El caso de las RGFO tipo PKA}

Este tipo de RGFO se encuentra representado en cinco NS y en dos NM. Los NS están conforma-

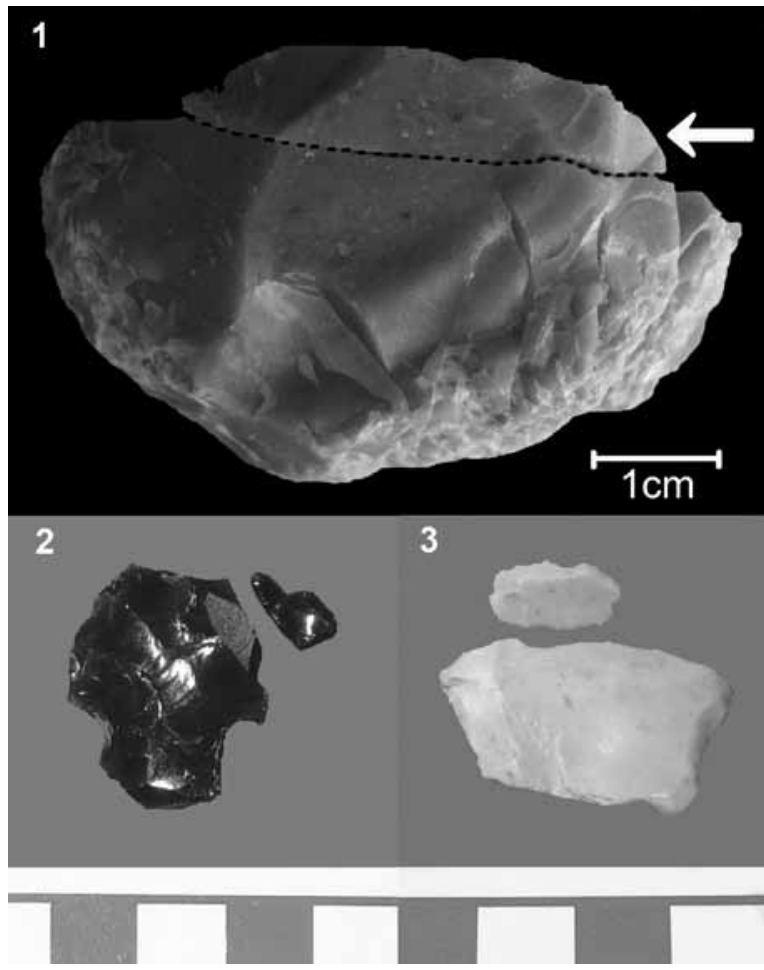

Fig. 6. Casos de remontaje entre los artefactos líticos recuperados en laguna Cóndor.

dos por tres desechos aislados y dos instrumentos aislados, tratándose en este último caso de dos puntas de proyectil semejantes morfológicamente a las denominadas Bird IV (Bird 1993). De hecho, las RGFO tipo PKA son la materia prima preferentemente seleccionada entre las rocas volcánicas para la manufactura de las puntas de proyectil en el CVPA. Se trata de un fragmento de limbo y de un espécimen entero con pedúnculo diferenciado y hombros, sin corteza, con un largo máximo de $26,54 \mathrm{~mm}$ y muy reactivado en los bordes del limbo. Ambas piezas parecerían representar, en un caso, el descarte por su fractura durante el uso, y en el otro por encontrarse al final de su vida útil.

Los desechos aislados son en todos los casos lascas angulares, en tamaños comprendidos entre 33 y 38 mm (diámetro máximo), dos de ellas con ausencia de corteza y la tercera con un $10 \%$ representado. Presentan entre 5 y 6 extracciones previas en la cara dorsal. Estas variables sugieren que estos desechos pueden ser considerados como el producto del mantenimiento de instrumentos transportados. 
Tabla 9. Casos de reparación y ensamblaje según clase tipológica.

\begin{tabular}{|c|c|c|c|c|c|}
\hline \multicolumn{3}{|c|}{ Remontaje $(\mathrm{n}=13)$} & \multicolumn{3}{c|}{ Reparación $(\mathrm{n}=5)$} \\
\hline $\mathrm{D} / \mathrm{D}$ & $\mathrm{D} / \mathrm{I}$ & $\mathrm{D} / \mathrm{N}$ & $\mathrm{D} / \mathrm{D}$ & $\mathrm{I} / \mathrm{I}$ & $\mathrm{N} / \mathrm{N}$ \\
\hline 10 & 2 & 1 & 4 & 1 & 0 \\
\hline
\end{tabular}

D: desecho de talla, I: instrumento, N: núcleo

Los NM están compuestos por un conjunto de un núcleo bipolar junto con dos desechos de talla y otros dos desechos correspondientes a otro nódulo. El núcleo es muy pequeño $(25,88 \times 21,05 \times 8,3$ $\mathrm{mm})$ y presenta la densidad de extracciones más elevada entre los siete núcleos que se han recuperado en el sitio (dos extracciones por $\mathrm{mm}^{3}$ ). El mismo se encuentra acompañado por una lasca de reactivación directa (sensu Aschero 1983) y una lasca angular. Esto sugiere el descarte de un núcleo agotado sobre una materia prima no-local en cercanías de una fuente de aprovisionamiento donde es posible reabastecerse de recursos líticos. Los dos desechos restantes, pertenecientes a otro nódulo, también apuntan hacia el desarrollo de actividades de mantenimiento, como en los casos previos, ya que se trata de una lasca angular de tamaño pequeño (33,6 mm de largo máximo), sin corteza y con cinco extracciones previas, junto con un fragmento distal de este mismo tipo de lasca. Todas estas evidencias indican una estrategia de conservación sobre los instrumentos manufacturados en RGFO tipo PKA, los cuales formarían parte del toolkit transportado, como así también los núcleos de esta roca, ya que no se encuentra disponible localmente.

\section{DISCUSIÓN}

Dos tipos de estrategias de aprovisionamiento (sensu Kuhn 2004) se encuentran representadas en el conjunto de laguna Cóndor. Por un lado, el predominio de NS, en su mayoría representados por desechos aislados entre los que se encuentran presentes materias primas no-locales (como la obsidiana verde y la RGFO tipo PKA), indica la reactivación de instrumentos que transitaron por el sitio formando parte del equipo transportado, lo cual sugiere una estrategia de aprovisionamiento de individuos (Kuhn 2004) y de conservación de los artefactos (Binford 1979). Por otro lado, la presencia de instrumentos de gran tamaño (no transportables), con vida útil potencial y con morfologías que apuntan hacia usos específicos, posiblemente relacionados con la explotación de la madera (como los cepillos, choppers y chooppings tools), son entendidos en el marco de una estrategia de aprovisionamiento de lugares (Kuhn 2004). Esta estrategia tecnológica implica una previsión de regreso al lugar, lo cual sugiere el uso de este espacio de forma planificada y recurrente, posiblemente en un marco logístico (Charlin et al. 2011). Como ha sido sugerido en otro lado (Pallo y Charlin 2010), el uso de este espacio debe ser entendido en términos estacionales, ya que de acuerdo con la altitud, longitud y pendiente del terreno, las heladas -durante casi todo el año- y las nevadas -en invierno- son frecuentes. Estos factores convierten a estos espacios occidentales en desfavorables para la ocupación humana durante las estaciones más frías. En este marco, es importante tener en cuenta que el "riesgo estacional" ha mostrado ser el factor ambiental que mayormente explica la distribución de los tipos de artefactos en una escala regional de análisis (Pallo y Charlin 2010).

Previamente a nuestros trabajos en esta zona, Carballo Marina et al. (2008: 208) propusieron un uso homogéneo del espacio [de la cuenca del Gallegos] en términos de las actividades desarrolladas. Consideramos que actualmente esta hipótesis debe ser revisada frente a las nuevas evidencias aquí presentadas, dado que este sector del espacio muestra un panorama diferente al observado en otras porciones del río Gallegos. Si bien en el conjunto recuperado en laguna Cóndor no se observa una diversidad diferencial del conjunto lítico (en cuanto a los tipos de artefactos representados), llama la atención la presencia de los grandes cepillos, choppers y chopping tools, que si bien no constituyen "tipos" de artefactos exóticos, parecen ser más abundantes en este contexto (algunas veces conformando instrumentos compuestos), en cercanías del bosque, que aquellos recuperados en sectores más alejados. Una propuesta similar fue sugerida por Borrazzo (2005) en relación con los materiales de Cerro León 3, sitio localizado en las estribaciones SE de la cordillera Baguales, sector cubierto de bosques durante buena parte del Holoceno (Borrero et al. 2006). Esta hipótesis queda abierta para ser testeada contra futuras evidencias y en un margo regional. Asimismo, evidencias de equipamiento de sitio, como fue sugerido aquí, no han sido observadas en los sitios del CVPA, aunque 
Tabla 10. Proporción de artefactos en obsidiana gris-verdosa veteada (ObGV) en los sitios del CVPA y en laguna Cóndor.

\begin{tabular}{|l|l|c|c|c|}
\hline \multicolumn{1}{|c|}{ Sitio } & \multicolumn{1}{|c|}{ Relevamiento } & Frecuencia artefactos & Total artefactos & $\begin{array}{c}\text { Proporción artefactos } \\
\text { ObGV }\end{array}$ \\
\hline Laguna Cóndor & Superficie margen NE & 10 & 280 & 0,036 \\
\hline Cóndor 1 & Talud 1 & 1 & 731 & 0,0014 \\
\hline Cóndor 1 & Talud 2 & 1 & 399 & 0,002 \\
\hline Cóndor 1 & Cuadríc. 12H & 20 & 6177 & 0,003 \\
\hline Cóndor 1 & Cuadríc. 4E & 15 & 3266 & 0,0045 \\
\hline Norte 1 & Sondeo 1 & 1 & 845 & 0,0012 \\
\hline Frailes 2 & Superficie alero & 4 & 1194 & 0,0034 \\
\hline
\end{tabular}

relevamientos recientes en la laguna Potrok Aike parecen brindar algunas evidencias en este sentido, quizás en relación también con un uso estacional y logístico de esta laguna (Charlin 2008).

Por último, podemos señalar que la frecuencia de artefactos en obsidiana gris-verdosa veteada recuperados en laguna Cóndor, especialmente de un núcleo y de una preforma de punta de proyectil, podrían estar sugiriendo que este sector del espacio formaba parte de la vía de acceso hacia la fuente potencial de aprovisionamiento de esta roca. De hecho la comparación de la proporción de artefactos manufacturados sobre este tipo de obsidiana entre laguna Cóndor y los sitios del CVPA, señala la mayor abundancia en este contexto, aunque no se observa una tendencia de decrecimiento lineal en relación con la distancia (tabla 10).

\section{CONCLUSIONES}

La asociación de algunos de los artefactos líticos recuperados en la laguna Cóndor con fragmentos de vidrio, metal y fauna europea, junto con las dataciones radiocarbónicas obtenidas, señala la formación de los conjuntos en momentos históricos, al menos para parte de la muestra, lo cual es concordante con la información para el área aportada por cronistas y viajeros.

Sin embargo, este sector del espacio fue explotado por las poblaciones pasadas desde momentos previos, en tanto en ninguno de los trabajos mencionados en los antecedentes se indica la presencia de elementos foráneos en los contextos arqueológicos descriptos (Carballo Marina et al. 2008; Gómez Otero 1991; Molinari 2000; Prieto 1984; Ortiz Troncoso 1993). Si bien no se cuenta con fechados directos para ninguno de los entierros en los morros, los mismos han sido asignados a la Unidad Cultural Tardía (sensu Massone 1981), la cual comprende los últimos 5.000 años AP. El mismo panorama puede extenderse a las representaciones rupestres registradas en morro Chico (Bate 1970). Si bien el marco temporal del estilo "Río Chico" aún no se encuentra bien definido (Bate 1970; Gallardo 2009), la evidencia aportada por algunos pigmentos recuperados en estratigrafía ubica su desarrollo al menos entre ca. 2000-850 AP (Gómez Otero 19891990; Prieto et al. 1998).

Estas evidencias, sumadas a las presentadas en este trabajo, sugieren un uso recurrente de este sector del espacio a lo largo del Holoceno tardío, que si bien no fue tan intenso como el registrado en otras áreas del río Gallegos, el mismo fue planificado y podría sugerirse, con objetivos específicos, ya sea como lugar de entierro, como ruta de acceso a la sierra Baguales o para la explotación de los recursos del bosque (aunque estas dos últimas posibilidades quedan planteadas a modo de hipótesis).

Con respecto a la metodología de análisis aquí implementada, cabe señalar las potencialidades del MANA para evaluar las estrategias de aprovisionamiento y explotación principalmente de materiales exóticos, como las obsidianas. En el caso de estudio aquí presentado ha permitido cuantificar la cantidad de nódulos explotados de la variedad gris-verdosa veteada (número mínimo) y de acuerdo con su tamaño y composición nos posibilitó precisar la forma de acceso a esta fuente. Cabe señalar la importancia de la textura superficial (corteza) como rasgo diagnóstico para la discriminación de nódulos en estos casos.

Si bien es de destacar la potencialidad del MANA como método de cuantificación, luego de su aplicación consideramos que su operatividad se encontraría reducida en conjuntos artefactuales grandes y/o en aquellos en los que abunden los desechos de talla. Esta observación no resta valor al método, pero constituye un limitante a la 
hora de encarar el trabajo de laboratorio. Por otro lado, si en la muestra predominan los desechos de talla, sobre todo aquellos producto de los estadios finales de manufactura o mantenimiento de los artefactos, la ausencia de rasgos que resultan claves para la identificación de un nódulo (como puede serlo la textura superficial) asociados al tamaño pequeño de las piezas, dificultan la tarea. A pesar de estas limitantes, consideramos que el MANA es un método de gran utilidad para evaluar las estrategias tecnológicas y el uso del espacio en una escala amplia, ya que constituye una valiosa herramienta para la cuantificación de las materias primas, permitiendo estandarizar las comparaciones entre sitios.

\section{AGRADECIMEINTOS}

Este trabajo formó parte de los proyectos PIP-CONICET № 5676 y PICT-ANPCyT № 2046, dirigidos por el Dr. Luis Borrero. Mis agradecimientos en particular a la Dra. Roxana Cattáneo, quien me introdujo en la práctica de esta metodología de análisis y me facilitó numerosa bibliografía y a la Dra. María Clara Etchichury, quien me instruye y asesora en la identificación macroscópica de rocas, además de ocuparse de la determinación petrográfica de los cortes delgados. También les agradezco enormemente a los evaluadores del manuscrito quienes han realizado valiosas sugerencias que mejoraron la presentación del trabajo.

Los agradecimientos del equipo en general son para la familia Menéndez y Tomás Ibañez, por la predisposición y hospitalidad mostrada durante el desarrollo de los trabajos de campo.

\section{BIBLIOGRAFÍA}

ALBERTI, J. 2010. Fuentes de rocas y uso de materias primas líticas en la costa norte del golfo San Matías (provincia de Río Negro, Argentina). Tesis de licenciatura de la Facultad de Filosofía y Letras de la Universidad de Buenos Aires. MS.

ARAGÓN, E. Y N. FRANCO. 1997. Características de rocas para la talla por percusión y propiedades petrográficas. Anales del Instituto de la Patagonia 25: 187-199.

ASCHERO, C. 1975. Ensayo para una clasificación morfológica de artefactos líticos aplicada a estudios tipológicos comparativos. Informe entregado al CONICET. MS.
1983. Ensayo para una clasificación morfológica de artefactos líticos aplicada a estudios tipológicos comparativos. Revisión. Cátedra de Ergología y Tecnología (FFyL-UBA). Buenos Aires. MS.

ASCHERO, C. Y S. HOCSMAN. 2004 Revisando cuestiones tipológicas en torno a la clasificación de artefactos bifaciales. En: Temas de Arqueología. Análisis lítico, compilado por A. Acosta, D. Loponte y M. Ramos, pp. 7-25. Universidad Nacional de Luján. Buenos Aires.

BACKHOUSE, P. Y E. JOHNSON. 2007. Where were the hearths: an experimental investigation of the archaeological signature of prehistoric fire technology in the alluvial gravels of the Southern Plains. Journal of Archaeological Science 34:1367-1378.

BATE, L. F. 1970. Primeras investigaciones sobre el arte rupestre de la Patagonia chilena. Anales del Instituto de la Patagonia 1 (1): 15-26.

1971. Primeras investigaciones sobre el arte rupestre de la Patagonia chilena (segundo informe). Anales del Instituto de la Patagonia 2: 33-41.

BIRD, J. 1993. Viajes y Arqueología en Chile Austral. Ed. por J. Hyslop. Ediciones de la Universidad de Magallanes, Punta Arenas.

BINFORD, L. 1979. Organization and formation processes: looking at curated technologies. Journal of Anthropological Research 35: 255-273.

BORRAZZO, K. 2005. Al Sur de Baguales: cambio tecnológico y uso del espacio. En: Libro de resúmenes VI Jornadas de Arqueología de la Patagonia, p.23. Punta Arenas 2006. Tecnología lítica del alero Cerro León 3 (Santa Cruz, Argentina). Magallania 34 (2):63-74.

2008. Análisis tecnológico de distribuciones artefactuales en la periferia sudeste de la sierra Baguales (Santa Cruz, Argentina). Magallania 36(1):103-116.

BORRERO, L. 1980. La Fauna de Las Buitreras: su significado en un marco sudamericano. Runa XIII (1-2): 21- 30.

BORRERO, L. Y J. CHARLIN. 2010. Arqueología del campo volcánico Pali Aike. En: Arqueología de Pali Aike y Cabo Vírgenes (Prov. Santa Cruz, Argentina), editado por L. Borrero y J. Charlin, cap. 1, pp. 9-30. CONICETIMHICIHU, Editorial Dunken. Buenos Aires.

BORRERO, L., N. FRANCO, F. MARTIN, R. BARBERENA, R. GUICHÓN, J. BELARDI, C. FAVIER DUBOIS Y L. L'HEUREUX. 2006. Las cabeceras del Coyle: información arqueológica y circulación de poblaciones humanas. En: La cuenca del río Coyle. Estado actual de las investigaciones, editado por J. Belardi, Carballo Marina y S. Espinosa, cap. 4, pp. 75-95, Ed. Universidad Nacional de la Patagonia Austral. Río Gallegos. 
CAMPAN, P., F. CARBALLO MARINA Y L. MANZI. 2007. Arqueología de estancia La Carlota (campo volcánico Pali Aike, Santa Cruz). En: Arqueología de Fuego-Patagonia. Levantando piedras, desenterrando huesos... y develando arcanos, editado por F. Morello, M. Martinic, A. Prieto y G. Bahamonde, pp. 687-699, Ediciones CEQUA, Punta Arenas.

CARBALLO MARINA, F. Y B. ERCOLANO. 2004. El uso humano de las marismas del río Gallegos durante el Holoceno. En: Actas de las II Jornadas Patagónicas Mallines y Humedales. Universidad Nacional de la Patagonia Austral, Unidad Académica Río Gallegos (ed.). Río Gallegos. CD-ROM.

2007. Arqueología de Punta Loyola, margen sur del estuario del río Gallegos (Santa Cruz). En: Arqueología Argentina en los inicios de un nuevo siglo, F. Oliva, Nélida de Grandis y J. Rodrigues (comp.), tomo I, pp. 319-328. Universidad Nacional de Rosario, Laborde Editores. Santa Fé.

CARBALLO MARINA, F., B. ERCOLANO, E. MAZZONI Y M. VÁZQUEZ. 2000. Las unidades de paisaje y la distribución de artefactos en el valle inferior del río Gallegos. En: Desde el país de los gigantes. Perspectivas arqueológicas de Patagonia. Universidad Nacional de la Patagonia Austral (ed.), pp. 331-343. Río Gallegos.

CARBALLO MARINA, F., L. MANZI, P. CAMPAN, J. B. BELARDI, P. TIBERI, A. MANERA Y J. L. SÁENZ. 2008. Distribución del registro arqueológico en la cuenca del río Gallegos (Santa Cruz): línea de base y aporte a la preservación del patrimonio. En: Arqueología del extremo sur del continente americano, L. A. Borrero y N. V. Franco (comps.), pp. 175- 225. CONICETIMHICIHU, Buenos Aires.

CARDILLO, M. 2009. Variabilidad en la manufactura y diseño de los artefactos en el área costera patagónica. Un enfoque integrador. Tesis para optar al grado de doctor. Facultad de Filosofía y Letras, Universidad de Buenos Aires. Buenos Aires. MS.

CATTÁNEO, R. 2002. Una aproximación a la organización de la Tecnología Lítica entre los cazadores-recolectores del Holoceno Medio/Pleistoceno Final en la Patagonia Austral (Argentina). Tesis para optar al grado de doctor, Facultad de Ciencias Naturales y Museo, Universidad Nacional de La Plata. La Plata. MS.

2004. El estudio de la variabilidad a través de los conjuntos de desechos líticos. Resúmenes del Taller de morfología macroscópica en la clasificación de artefactos líticos: innovaciones y perspectivas. Instituto de Arqueología y Museo. Universidad Nacional de Tucumán. Horco Molle, Tucumán.

2005. Tecnología lítica en la Localidad Arqueológica Piedra Museo (Santa Cruz, Argentina). Relaciones de la Sociedad Argentina de Antropología XXX: 79-103.

CORBELLA, H. Y B. ERCOLANO. 2002. Acerca del valle medio e inferior del río Gallegos. Patagonia austral Argentina. Actas del XV Congreso Geológico Argentino, pp. 661-666. El Calafate.

CHARLIN, J. 2005. Aprovisionamiento de materias primas líticas en el campo volcánico de Pali Aike (Santa Cruz): una primera aproximación a partir del análisis de los núcleos. Werken 7: 39-58.

2007. Explorando la intensidad de uso de las materias primas líticas en Pali Aike (Prov. Santa Cruz, Argentina). Intersecciones en Antropología 8:287-299.

2008. Abastecimiento, explotación y circulación de materias primas líticas en el extremo sur de Patagonia meridional, PICT 2008 № 15 (2010-2012). MS.

2009a. A más de 30 años: otra mirada a la tecnología lítica de Las Buitreras 1 (cuenca del río Gallegos, Santa Cruz). Intersecciones en Antropología 10: 237-248.

2009b. Estrategias de aprovisionamiento y utilización de las materias primas líticas en el campo volcánico Pali Aike (Prov. Santa Cruz, Argentina). British Archaeological Reports, Internacional Series 1901, Archaeopress, Oxford.

2009c. Aprovisionamiento, explotación y circulación de obsidianas durante el Holoceno tardío en Pali Aike (Prov. Santa Cruz). Relaciones de la Sociedad Argentina de Antropología XXXIV: 53-74.

CHARLIN, J. Y M. D'ORAZIO. 2011. Fuentes primarias vs. secundarias de aprovisionamiento lítico: una comparación geoquímica (Pali Aike, Santa Cruz). En: La Arqueometría en Argentina y Latinoamérica, editado por Bertolino, S., Cattaneo, G. R y A. D. Izeta, pp. 153-158. Editorial de la FFyH, Universidad Nacional de Córdoba. Córdoba.

CHARLIN, J. Y M. C. PALLO. 2012. Disponibilidad de materias primas líticas y uso del espacio en el interfluvio Gallegos-Chico (Pali Aike, Santa Cruz, Argentina). En: Actas de las VIII Jornadas de Arqueología de la Patagonia, Malargüe. En prensa.

CHARLIN, J., N. FRANCO Y M. D'ORAZIO. 2010. El campo volcánico Pali Aike y las fuentes potenciales de aprovisionamiento lítico: primeros resultados geoquímicos. En: Arqueología de Pali Aike y Cabo Vírgenes (Prov. Santa Cruz, Argentina), editado por L. Borrero y J. Charlin, cap. 2, pp. 31-54. CONICET-IMHICIHU, Editorial Dunken. Buenos Aires. 
CHARLIN, J., L. BORRERO Y M. CECILIA PALLO. 2011. Ocupaciones humanas en el área noroccidental del río Gallegos (Prov. Santa Cruz, Argentina). En: Bosques, montañas y cazadores: biogeografía en Patagonia meridional, editado por L. A. Borrero y K. Borrazzo, pp. 179-210. CONICET-IMHICIHU. Buenos Aires.

D'ORAZIO, M., AGOSTINI, S., INNOCENTI, F., HALLER, M. J., MANETTI, P. Y MAZZARINI, F. 2001. Slab window-related magmatism from southernmost South America: the Late Miocene mafic volcanics from the Estancia Glencross area (52으, Argentina-Chile). Lithos 57: 67-89.

ERCOLANO, B. Y F. CARBALLO MARINA. 2005. Cazadores recolectores de la boca del estuario del río Gallegos, Santa Cruz, Argentina. Magallania 33 (2): 109-126.

ERCOLANO, B., F. CARBALLO MARINA Y E. MAZZONI. 2000. El uso del espacio por parte de las poblaciones cazadoras-recolectoras en la cuenca inferior del río Gallegos, extremo sur de Patagonia, Argentina. Anales del Instituto de la Patagonia 28: 233-250.

FERNANDEZ, M. V. 2009. Disponibilidad y uso de materias primas líticas en el área de Los Antiguos y Monte Zeballos (Santa Cruz, Argentina). Tesis de licenciatura de la Facultad de Filosofía y Letras de la Universidad de Buenos Aires. MS.

FLEGENHEIMER, N. Y C. BAYÓN. 1999. Abastecimiento de rocas en sitios pampeanos tempranos: recolectando colores. En: En los tres reinos: Prácticas de recolección en el cono sur de América, C. Aschero, M. Korstanje y P. Vuoto (eds.), pp. 95-110, Instituto de Arqueología y Museo, Facultad de Ciencias Naturales e Instituto Manuel Lillo, Universidad Nacional de Tucumán. Ediciones Magna Publicaciones. San Miguel de Tucumán.

FLEGENHEIMER, N. Y R. CATTÁNEO. 2010. Producción lítica a través del espacio: análisis comparativo en contextos del Pleistoceno final/Holoceno temprano de Chile y Argentina. En: Libro de resúmenes V Simposio Internacional "El hombre temprano en América", D. Hermo y R. Blanco comps, Cooperativa gráfica El Río Suena. La Plata.

FRANCO, N. 2002. Estrategias de utilización de recursos líticos en la cuenca superior del Río Santa Cruz. Tesis doctoral. Facultad de Filosofía y Letras. Universidad de Buenos Aires. Buenos Aires. MS.

FRANCO, N. Y E. ARAGÓN. 2002. Muestreo de fuentes potenciales de aprovisionamiento lítico: un caso de estudio. En: Del mar a los salitrales. Diez mil años de historia pampeana en el umbral del tercer milenio, ed. por $\mathrm{D}$. Mazzanti, M. Berón y F. Oliva, pp. 243-250. Univer- sidad Nacional de Mar del Plata y Sociedad Argentina de Antropología, Buenos Aires.

2004. Variabilidad en fuentes secundarias de aprovisionamiento lítico: El caso del sur del lago Argentino (Santa Cruz, Argentina). Estudios Atacameños 28:71-85.

FRANCO, N. Y L. BORRERO. 1999. Metodología de análisis de la estructura regional de recursos líticos. En: En Los tres Reinos: Prácticas de recolección en el cono Sur de América, editado por C. Aschero, M. Korstanje y P. Vuoto, pp. 27-37, Ediciones Magna Publicaciones, Universidad Nacional de Tucumán. San Miguel de Tucumán.

GALLARDO, F. Sobre la composición y disposición en el arte rupestre de Chile: Consideraciones metodológicas e interpretativas. Magallania 37 (1):85-98.

GÓMEZ OTERO, J. 1991. Discusión sobre el límite occidental del territorio de los Proto-Tehuelches y Tehuelches meridionales en el extremo Sud de Patagonia (cuenca del río Gallegos). Waxen 3: 5-21.

1989-1990. Cazadores tardíos en la zona fronteriza del paralelo $52^{\circ}$ sur. El paraje de Juni Aike. Anales del Instituto de la Patagonia 19: 47-71.

GÓMEZ OTERO, J. Y M. V. FONTANELLA. 1980. Informe sobre una prospección arqueológica en el extremo sur de la Provincia de Santa Cruz. Karu-Kinka: 91-108.

KUHN, S. 2004. Upper Paleolithic raw material economies at Ücagizli cave, Turkey. Journal of Anthropological Archaeology 23: 431-448.

LARSON, M. L. 1994. Toward a holistic analysis of chipped stone assemblages. En: The organization of North American Prehistoric chipped stone tool technologies, editado por P. Carr, Cap. 5, pp. 57-69. International Monographs in Prehistory, Archaeological Series 7. Ann Arbor, Michigan.

2004. Chipped stone aggregate analysis in Archaeology. En: Aggregate analysis in chipped stone, editado por C. Hall y M. L. Larson, cap. 1, pp. 3-17. University of Utah press, Salt Lake city.

LARSON, M. L. Y M. KORNFELD. 1997. Chipped stone nodules: Theory, method, and examples. Lithic Technology 22 (1): 4-18.

LARSON, M. L. Y J. FINLEY. 2004. Seeing the trees but missing the forest: production sequences and multiple linear regression. En: Aggregate analysis in chipped stone, editado por Hall C. y M. L. Larson, cap. 5, pp. 95-111. University of Utah press, Salt Lake city.

MANSUR, M. E., A. LASA Y M. VÁZQUEZ. 2004. Investigaciones arqueológicas en Punta Bustamante, Prov. de Santa Cruz: El sitio RUD01 bk. En: Contra viento y 
marea. Arqueología de Patagonia. M. T. Civalero, P. M. Fernández y A. G. Guráieb (comps.), pp. 755-774. Instituto Nacional de Antropología y Pensamiento Latinoamericano y Sociedad Argentina de Antropología, Buenos Aires.

MASSONE, M. 1981. Arqueología de la región volcánica de Pali Aike (Patagonia Meridional Chilena). Anales del Instituto de la Patagonia 12: 95-121.

MEGLIOLI, A. 1992. Glacial geology and chronology of southernmost Patagonia and Tierra del Fuego, Argentina and Chile. Tesis doctoral. Universidad de Lehigh. Bethlehem, Pennsylvania. MS.

MOLINA, MANUEL. 1969-1970. El abrigo de los pescadores (Prov. Santa Cruz). Anales de Arqueología y Etnología XXIV/XXV. Universidad Nacional de Cuyo, Mendoza. 1976. Patagonia, Prehistoria, Tradición y Mitologías. Universidad de la Patagonia "San Juan Bosco", Comodoro Rivadavia.

MOLINARI, R. 2000. Relevamiento arqueológico en la estancia Rincón de los Morros (Santa Cruz). MS.

MARTINIC, M. 1995. Los Aónikenk. Historia y cultura. Ediciones Universidad de Magallanes. Punta Arenas.

ORTIZ TRONCOSO, O. 1973. Artefactos de silex de una tumba de morro Philippi, valle medio del río Gallegos (Prov. de Santa Cruz, Rep. Argentina). Anales del Instituto de la Patagonia IV (1-3): 131-139.

PALLO, M. C. Y J. CHARLIN. 2010. Distribución de artefactos y variabilidad ambiental en el extremo sur de Patagonia (Pali Aike, Santa Cruz). En: Arqueología Argentina en el Bicentenario de la Revolución de Mayo, J. R. Bárcena y H. Chiavazza (eds.), tomo I, cap. 1, pp. 31-36. Facultad de Filosofía y Letras de la Universidad Nacional de Cuyo, INCIHUSA-CONICET y ANPCyT. Mendoza.

PAUTASSI, E. Y G. SARIO. 2010. Central nuclear 2, valle de Calamuchita (Córdoba, Argentina), una aproximación experimental en reducción de núcleos. En: Arqueología Argentina en el Bicentenario de la Revolución de Mayo, editado por J. R. Bárcena y H. Chiavazza, tomo I, cap. 1, pp. 43-48. Facultad de Filosofía y Letras de la Universidad Nacional de Cuyo, INCIHUSA-CONICET y ANPCyT, Mendoza.

PRIETO, A. 1984. Hallazgo de un colgante decorado en Morro Chico (Magallanes). Anales del Instituto de la Patagonia 14:59-61.

1993-1994 Algunos datos en torno a los enterratorios humanos de la región continental de Magallanes. Anales del Instituto de la Patagonia 22: 91-99.

PRIETO, A., F. MORELLO, R. CÁRDENAS Y M. CHRISTENSEN. 1998. Cañadón Leona: A sesenta años de su descubrimiento. Anales del Instituto de la Patagonia, 26: 83-105.

RAMOS, M. 1993. Propuesta terminológica para la técnica arqueológica del ensamblaje. Arqueología 3:199-212. Buenos Aires

RATTO, N. 1991. Elección de rocas y diseño de artefactos: propiedades físico-mecánicas de las materias primas líticas del sitio arqueológico Inca Cueva c-4 (Jujuy, Argentina). Actas del XI Congreso Nacional de Arqueología Chilena. TII, Santiago de Chile.

RATTO, N. Y D. KLIGMAN, 1992. Esquema de clasificación de materias primas líticas arqueológicas en Tierra del fuego: Intento de unificación y aplicación a dos casos de análisis. Arqueología 2: 107-134.

SARIO, G. 2009. Estancia La Suiza 3 (Provincia de San Luis): Un estudio de la tecnología lítica. La Zaranda de Ideas 5: $45-64$.

SANGUINETTI DE BÓRMIDA, A. 1976. Excavaciones prehistóricas en la cueva de Las Buitreras, Santa Cruz, Argentina. Relaciones de la Sociedad Argentina de Antropología X: 271-292.

1976-1980. El sitio Las Buitreras como aporte al manejo de fuentes prehistóricas del temprano poblamiento sudamericano. Runa XIII (1-2):11-25.

1982. Introducción a la prehistoria de la Patagonia Argentina. Tesis doctoral. Facultad de Filosofía y Letras, Universidad de Buenos Aires. Buenos Aires. MS.

1999. Informe sobre las investigaciones llevadas a cabo en el área de investigaciones de la cuenca del río Gallegos (Provincia de Santa Cruz, Argentina). Praehistoria 3: 119-133.

SANGUINETTI DE BÓRMIDA, A. Y L. BORRERO 1977. Los niveles con fauna extinta de la cueva Las Buitreras (Río Gallegos, Provincia de Santa Cruz). Relaciones de la Sociedad Argentina de Antropología, XI: 167-178.

1983. Las Buitreras cave and the palaeoenvironments of the río Gallegos valley, Province of Santa Cruz, Argentina. Quaternary of south America and Antartic peninsula 1: 151-156.

SCASSO, R. A. Y C. O. LIMARINO 1997. Petrología y diagénesis de rocas clásticas. Asociación Argentina de Sedimentología. Publicación especial nº 1. Buenos Aires.

STERN, C. 2004. Obsidian in southern Patagonia: Review of the current information. En: Contra viento y marea. Arqueología de Patagonia, editado por M. T. Civalero, P. M. Fernández y A. G. Guráieb, Instituto Nacional de Antropología y Pensamiento Latinoamericano y Sociedad Argentina de Antropología, pp.168-176. Buenos Aires. 
STERN, C. Y N. FRANCO 2000. Obsidiana gris verdosa veteada en la cuenca superior del río Santa Cruz, extremo sur de Patagonia. Anales del Instituto de la Patagonia 28: 265-273.

SULLIVAN, A. P. Y K. C. ROZEN 1985. Debitage analysis and archaeological interpretation. American Antiquity 50: 755-779.
TERUGGI, M. 1984. Diccionario sedimentológico. Volumen II, Rocas aclásticas y suelos. Ediciones Científicas Argentinas, Librart. Buenos Aires.

WEITZEL, C. Y M. COLOMBO 2006. ¿Qué hacemos con los fragmentos? Un experimento en fractura de artefactos líticos tallados. La Zaranda de Ideas 2: 23-37. 